\title{
UM FILÓSOFO-REI NAS ARCADAS \\ (SAUDAÇÃO AO PROF. TÉRCIO SAMPAIO FERRAZ JUNIOR POR OCASIÃO \\ DE SUA POSSE NA ACADEMIA PAULISTA DE DIREITO)
}

A KING-PHILOSOPHER IN ARCADES (GREETING TO FULL PROFESSOR TERCIO

SAMPAIO FERRAZ JUNIOR DUE TO HIS INVESTITURE IN THE PAULIST ACADEMY OF

LAW

Luís Eduardo Schoueri*

Exmo. Sr. Prof. Titular João Grandino Rodas, DD. Diretor da Faculdade de Direito da Universidade de São Paulo;

Exmo. Sr. Prof. Titular Roque Antônio Carrazza, DD. Presidente da Academia Paulista de Direito;

Exmo. Sr. Prof. Titular Tércio Sampaio Ferraz Júnior, DD. Empossando;

Caros Confrades da Academia Paulista de Direito;

Exmos. Srs. Professores da Faculdade de Direito da Universidade de São

Paulo;

Senhoras e Senhores,

À honra e à alegria presentes na missão de saudar o Prof. Tércio Sampaio Ferraz Junior, em nome dos demais acadêmicos, por ocasião de sua posse solene como Titular da Cadeira 38 da Academia Paulista de Direito, soma-se o dever de alertá-los de que esta saudação não obedece a ordem natural das coisas, pois felizmente, incluo-me entre seus pupilos e o normal seria estivesse ele nesta Academia muito antes do meu ingresso. Quis o acaso, entretanto, que o processo se invertesse e, com isso, no lugar da tradicional saudação do veterano ao calouro, tem-se o discípulo a abrir as portas para seu mestre.

Tércio é um paulista que soube honrar as tradições bandeirantes. Duas vezes bacharel pela Universidade de São Paulo (simultaneamente: Filosofia, de um lado e Ciências Jurídicas e Sociais, de outro), o novel acadêmico também é duas vezes doutor: em Filosofia, pela tradicionalíssima Johannes Gutemberg Universität de Mainz e em Direito, pela nossa Faculdade de Direito da USP. Nesta, após conquistar a LivreDocência em Filosofia do Direito, tornou-se Professor Titular em 1979, e é hoje o decano

\footnotetext{
* Professor Titular do Departamento de Direito Econômico, Financeiro e Tributário da Faculdade de Direito da Universidade de São Paulo.
} 
da Congregação das Arcadas. Também fruem de suas lições os estudantes da Pontifícia Universidade Católica de São Paulo, onde é Professor Titular, e da Faculdade Autônoma de Direito - FADISP.

Tenho cravadas em minha mente as lições do Prof. Tércio, nos bancos destas Arcadas. Suas aulas de Introdução ao Estudo de Direito são indeléveis. Os jovens ingressantes éramos surpreendidos por aulas de conteúdo erudito e forma tenra, próprias do então jovem Professor Titular. O Direito - este desconhecido - apresentava-se, na elegância argumentativa do professor, objeto de fascínio, apaixonante.

É precisamente no exemplo de Platão que encontro palavras para discorrer sobre o mestre que vem trazendo os fundamentos da filosofia aos jovens estudantes de Direito. Em seus "Diálogos", Platão retrata a forma como Sócrates, perquirindo consciências, leva seus discípulos ao aprendizado incessante. Também de diálogos valese Tércio para, nos dias atuais, conduzir os acadêmicos na propedêutica jurídica. Dotado de didática exemplar, ainda recordo de que jamais terminava sua preleção com uma "conclusão". As exposições de Tércio encerravam-se sempre com nova pergunta, elo para a aula seguinte. Este crescendo estimulava os alunos para o próximo encontro, quando, supostamente, a dúvida que atormentara a semana anterior seria resolvida. Contudo, como é próprio da abordagem zetética, a solução nunca era apresentada de forma resolutiva, cristalizada, apenas levava-nos a uma questão original, que mais uma vez, ingenuamente, ansiávamos traria o ponto derradeiro. Ainda lembro da última aula naquele ano de 1983: atrasado, mas ávido para não perder a preleção na qual - assim esperava - finalmente eu encontraria uma resposta (já que outro momento não haveria), cheguei mesmo a deixar meu carro no ponto de táxi do Largo de São Francisco. A previsível multa era, diante da ansiedade por não perder aquela ocasião, desprezível.

Dotado da legítima "alma de ouro" a que se referia Platão, nosso mestre houve por bem terminar com uma questão. Foi só então que verdadeiramente o compreendi como professor, e por conseqüência, o magistério. Propositadamente, o lente, motivaria seus alunos a investigarem com maior profundidade e afinco os temas da Teoria Geral do Direito. Movido por sincera admiração, nos anos seguintes, continuei ligado ao grande mestre. Ingressei, para tanto, no PET/CAPES, sob sua orientação e supervisão. Ali, meu interesse pela Teoria Geral do Direito amadureceu simultaneamente ao vínculo de amizade que nos traz ao dia de hoje.

A menção a Platão recorda-me a aula mais marcante de nosso sábio, quando este relatava o Mito da Caverna do Livro VII de "A República”, de Platão.

Conforme ensinava Tércio, nesta passagem o pensador grego descreve os homens, toda a humanidade, presos em uma caverna, acorrentados de modo a verem apenas seu fundo, a parede, onde se projetam sombras. Sem possibilidades de olhar para trás, os homens as tomam como realidade, melhor ainda, como a única e verdadeira 
realidade. Aquelas, na lição do professor, nada mais passavam que simulacro daquilo que era a verdade em essência, que ninguém poderia tomar conhecimento até que alguém - o filósofo - rompesse os grilhões e voltasse sua cabeça à entrada da caverna, de onde provinha toda a luz. Acessando-a, o filósofo era então capaz de contemplar as formas verdadeiras, as idéias, já livre das trevas.

Não é difícil identificar em Tércio o filósofo que "viu a luz". Vale, daí, continuar sua narrativa, já que ao descrever a missão do filósofo platônico, acaba por se auto retratar.

Admirável é a reação do filósofo depois de ver a luz: não guarda para si o conhecimento; ao contrário, retorna à caverna para compartilhar com os que ali ficaram o que lhe fora revelado. Ver a luz não the era o bastante. O filósofo via-se comprometido com a polis. Importava que outros também a contemplassem. Tragicamente, porém, é ridicularizado por discorrer sobre o desconhecido.

Frustrado, o filósofo de Platão, diante do dilema que lhe é imposto, confina-se em posição solitária, recorrendo a mitos como meio ideal na condução de seus semelhantes ao "bem". Como apenas a ele salta a verdade, usa a linguagem da ilusão para tratar da realidade. Passa então de filósofo a "rei-filósofo". Como enfatizava Tércio: "mais rei que filósofo".

É neste momento, entretanto, que o filósofo das Arcadas se destaca do filósofo de Platão. Este fica em posição solitária, conformando-se com as limitações de seus pares; Tércio não. Ele é professor, daqueles que abraçam o magistério como vocação. Vendo a luz, não permite que seus discípulos permaneçam acorrentados ao fundo da caverna.

Diante da rejeição dos que, comodamente, não aceitam novas teorias, Tércio se vale da teimosia do professor. Ele instiga. Provoca o raciocínio. O rompimento com as sombras é gradual, não necessariamente instantâneo.

A trajetória até a luz, sabidamente, não se faz sem percalços. Recorrendo mais uma vez à alegoria proposta, não é difícil imaginar que a luz - também ela - cause, inicialmente, cegueira. É assim o primeiro ano dos acadêmicos do Largo de São Francisco. É muita luz! Os que a buscarem não enfrentarão os obstáculos pioneiramente enfrentados pelo "filósofo-rei”, já que encontrarão um caminho já desbravado. Contarão com a mão firme do mestre Tércio, amparando-os.

Não posso deixar de lembrar de um colega do primeiro ano do Largo de São Francisco que confessava o terror que vivenciava nas aulas do Prof. Tércio. A impotência dos jovens calouros diante das palavras do Mestre é experiência recorrente. Retomando a figura da caverna, deve-se entender que para muitos, a luz ofusca e assusta. Não admira, muitos fujam do que viram e se voltem ao conforto do fundo da caverna, que, entretanto, já não terá a mesma acolhida. Será, quem sabe, a realidade escolhida, a mais fácil, a mais 
confortável, mas nunca a única. O acadêmico do Largo de São Francisco sabe que há a luz. Que outra realidade - posto que muitas vezes supostamente inacessível - prevalece sobre aquela que lhe é ordinariamente apresentada. Ocorre uma transformação na consciência de quem viu a luz. Esta marca, Tércio sabe que plantou em todos os que se sentaram em seus bancos escolares. No devido tempo - e cada um a seu tempo - todos vão compreendendo que a realidade fechada da dogmática jurídica não satisfaz. É como se, um a um, os alunos antes refratários fossem se voltando para trás, procurando a luz que uma vez os assustara. Sabem que podem se socorrer no apoio sereno do mestre Tércio.

Mas o filósofo de Platão - recordemos - não é apenas filósofo. É "reifilósofo". Rei porque conduz o povo. Tal condução não decorre do uso da força, mas do conhecimento, fruto da razão. O timoneiro, diria Tércio a partir das lições de Platão, tem conhecimento diferente dos que estão no barco, como o pastor se destaca de suas ovelhas ou o médico de seus pacientes.

Assim como o rei-filósofo, Tércio dedica-se à polis. Tércio, porém, não age como rei, mas como filósofo. Se aquele manipula, no melhor sentido que se possa extrair do termo, seu povo, o filósofo o instrui. Compartilha seu conhecimento, pondo-o à disposição de todos.

$\mathrm{Na}$ atuação de Tércio em nossa polis pode-se admirar ainda a rara união de Teoria e Práxis (e a palavra "práxis" é preferida à prática, já que aquela engloba algo além da atuação imediata, envolvendo toda a elaboração prévia à ação). Teórico invejável e praticante sagaz do direito, Tércio estabelece o elo necessário à prática ideal do "bem". Vive a práxis que prega, desempenhando brilhantemente o papel que lhe cabe na República (politéia em essência).

É, portanto, prestigiado detentor da característica mais cara aos gregos antigos, a arethé, excelência em seu grau superlativo.

No campo privado, é reconhecido como advogado brilhante. Antes de hoje se destacar como sócio de uma das mais respeitadas bancas de advocacia com vocação no Direito Econômico, chefiou o Departamento Jurídico da FIESP e foi diretor jurídico da Siemens.

Dedicado à causa pública (à República, no sentido platônico), foi secretário executivo do ministério da Justiça e procurador geral da Fazenda Nacional. Deste período remontam os mais precisos pareceres na seara tributária, fonte ainda hoje de rica pesquisa.

É com este espírito de eterna gratidão que hoje saúdo o Prof. Tércio Sampaio Ferraz Junior. Se há muito intitulo-me seu discípulo e, por sua concessão, hoje seu amigo, vejo com alegria a realidade de doravante tê-lo como confrade.

Agiganta-se a Academia Paulista de Direito! Um “filósofo-rei” se aproxima! Prof. Tércio Sampaio Ferraz Júnior: muito bem-vindo à sua Casa, nossa Academia. 